\title{
PRESENTACIÓN
}

\section{A 50 AÑOS DE LA REFORMA AGRARIA EN CHILE}

El 16 de julio de este 2017 se conmemoraron los 50 años de la promulgación de la Ley 16.640 de Reforma Agraria, sancionada en el gobierno de Eduardo Frei Montalva (1965-1970), aunque ya tenía antecedentes en la ley 15.020, promulgada durante la presidencia de Jorge Alessandri (1958-1964). Con el gobierno de la Unidad Popular de Salvador Allende el proceso se profundizó, terminando dramáticamente en 1973.

Son 50 años que la Universidad de Chile tiene el honor de conmemorar con esta edición de Anales dedicada a este momento de nuestra historia y a las discusiones que sigue generando hasta la actualidad.

Dignidad, ciudadanía y futuro. Se trata de tres palabras que nos emplazan a mirar la historia y comprender cómo en algunos momentos de Chile ha sido posible pensar el país, pensar a los campesinos y al campo más allá de los límites impuestos por la Colonia.

Lo anterior está en el centro de la Reforma Agraria, un profundo cambio cultural que surgió desde las bases del campesinado, la academia con sentido público, una Iglesia Católica comprometida con la justicia social y desde la convicción de partidos políticos que fueron corriendo los límites para profundizar la democracia en alianza con un pueblo que se movilizaba por transformaciones.

El Presidente Frei Montalva fue enfático al levantar este discurso al promulgarse la ley, y sería la creación de la Corporación de Reforma Agraria (CORA) el paso que materializaría e institucionalizaría esta decisión política, un referente mundial: "Esta ley tiene para nosotros un sentido claro. Ella no está inspirada en el odio, sino que tiene sólo como inspiración el afán de justicia. Sus objetivos ya han sido muchas veces esclarecidos: incorporar al campesino en plenitud a la vida social, económica y política de nuestra nación de la cual estaba, de hecho, en gran parte excluido. Abrir oportunidades para que los hombres de trabajo, de esfuerzo, puedan llegar a ser propietarios. Cambiar la estructura social y económica del campo chileno, terminando el desequilibrio que significa un avanzado proceso de desarrollo industrial junto con un régimen sumamente atrasado, y en ocasiones hasta feudal, en los campos, situación que implicaba tensiones, no sólo sociales, sino que contradicciones económicas imposibles de mantener y que llevarían al país entero a corto término a un fracaso". 
Unas 3,4 millones de hectáreas se lograron expropiar durante la Reforma Agraria de Frei Montalva (30\% de explotaciones y $40 \%$ de la tierra), beneficiando, según datos de la época, a 28 mil familias en cooperativas y asentamientos. Pero no fue suficiente, considerando la pobreza y la posibilidad de un desarrollo que no permitía salir de situaciones de explotación que vulneraban los derechos humanos. Así fue que durante el gobierno de Salvador Allende el descontento social se agudizó y entre enero de 1971 y junio de 1972 se aceleraron los cambios: se lograron expropiar 6,4 millones de hectáreas $(70 \%$ de la producción de los predios y $60 \%$ de la tierra) en medio de conflictos agudos en los campos chilenos.

En su discurso "Sobre la propiedad agrícola y la Reforma Agraria", ofrecido el 22 de agosto de 1971, el Presidente Salvador Allende fue enfático al referirse a los sentidos de esta revolución campesina (sus alcances históricos, sociales y culturales), profundizada durante los primeros años de la década de los setenta: "Que Reforma Agraria no es sólo, y es muy importante, el cambio de propiedad de la tierra, sino que, además, es hacer posible que el trabajador de ella, el campesino, el mediero, el afuerino, cambien su vida y su existencia, eleven su vida y su capacitación. Reforma Agraria es tierra, más crédito, semillas, abono, planificación, mecanización, sindicación de la tierra. Es educación y es salud. Reforma Agraria es hacer cierta la frase más que centenaria de Tupac Amaru, cuando decía, y lo hizo presente el Presidente del Perú al dictar la Ley de Reforma Agraria, 'el patrón no comerá más de tu sudor, compañero campesino' ”.

América Latina transitaba entre reformas y el mundo observaba estos cambios desde la promesa de futuro, por un lado, y desde la presión interventora, por el otro, y ya sabemos cómo terminó esta inflexión histórica que venía acompañada de movimientos continentales tanto en Chile como en toda la región. Las contrarreformas vinieron a narrar, desde el autoritarismo y la propiedad concentrada en unos pocos, un Chile que nos vuelve a interpelar a comienzos del siglo XXI.

Es precisamente por la profundidad de la interpelación que nos plantea la conmemoración de los 50 años de este hito que agradezco las reflexiones de Sergio Gómez, Octavio Avendaño, Manuel Antonio Garretón, José Bengoa, Pablo Ruiz Tagle, Carlos Furche, Grínor Rojo, Ximena Valdés, Sofía Correa, Pablo Mariman y Dan Carter, quienes con su acostumbrada lucidez intelectual presentan en este volumen discusiones que ahondan en las dimensiones sociales, culturales, políticas, de género, jurídicas y económicas, por nombrar algunas, relacionadas con este proceso. Agradezco a Alejandra Araya, directora del Archivo Central Andrés Bello, quien una vez más selecciona y pone en perspectiva crítica documentos del pasado que pueden ayudarnos a leer de manera más consciente 
nuestro presente. Agradezco, finalmente, la disposición de Jacques Chonchol, Ministro de Agricultura de Salvador Allende y pieza clave de este proceso, que con sus lúcidas respuestas evalúa los alcances de la Reforma Agraria desde la perspectiva actual.

Faride Zeran Chelech Directora de Anales de la Universidad de Chile Vicerrectora de Extensión y Comunicaciones Premio Nacional de Periodismo 2007 